\title{
Assessment of the Role of NOGO Gene Block in Enhancing the Neuro-regenerative Effect of Mesenchymal Stem Cells.
}

Eman Youssef ( $\square$ emannyoussef@gmail.com )

Cairo University Kasr Alainy Faculty of Medicine https://orcid.org/0000-0003-1931-4862

Hala Gabr

Cairo university Kasr Alainy Faculty of Medicine

Nirmeen A Kishk

cairo university Kasr Alainy Faculty of Medecine

Maha Baligh Zickri

cairo university Kasr Alainy Faculty of medecine

Shahira KA Botros

cairo university kasr alainy faculty of medecine

Amal S. Ashour

cairo university kasralainy faculty of medecin

\section{Research}

Keywords: Amyotrophic Lateral Sclerosis (ALS), Mesenchymal stem cells (MSCs), Neuroregeneration, NOGO A SiRNA

Posted Date: January 5th, 2021

DOl: https://doi.org/10.21203/rs.3.rs-137171/v1

License: (9) This work is licensed under a Creative Commons Attribution 4.0 International License. Read Full License 


\section{Abstract}

Background: Amyotrophic Lateral Sclerosis (ALS) is a fatal disease. Mesenchymal stem cells (MSCs) have a therapeutic potential in neuronal diseases, factors as NOGO-A limit axonal regeneration. In this study, gene silencing was used to suppress Nogo-A expression in MSCs to enhance its neuro-regenerative role.

Methods: mouse models of motor neuron degeneration were created, effect of non-modified and plasmid transfected MSCs were studied clinically and histologically. Group 1 received no treatment. Group 2 received IV injection of non modified MSCs and sacrificed after 8 days (subgroup 2a) and 15 days (subgroup 2b) following treatment, Group 3 received IV injection of transfected MSCs and were sacrificed after 8 days (subgroup 3a) and 15 days (subgroup 3b) following treatment.

Results: A significant increase in weight and motor scores of subgroups $2 a$ \& $2 b$ occurred in comparison to subgroups 1 a \& $1 \mathrm{~b}$ respectively ( $\mathrm{p}$ values $<0.001,<0.001,0.001 \& 0.026$ respectively), GAP43 expression in group 2 mice was significantly higher compared to group 1 mice ( $p$ value $<0.001$ ). Deformed neurons and glial cells in group 2 were significantly lower compared to group 1 mice ( $p$ value $<0.001$ ). Deformed neurons and glial cells in subgroup $2 \mathrm{~b}$ were significantly less in comparison to subgroup $2 \mathrm{a}$ ( $\mathrm{p}$ values $\mathbf{=} \mathbf{0 . 0 0 2}$ and $\mathbf{0 . 0 3}$ ) indicating an improvement with time. GAP43 in subgroup $2 \mathrm{~b}$ was significantly higher compared to subgroup $2 a(p$ value $=0.030$ ). Weight and motor power in group 3 mice was significantly higher when compared to group 1 on days; 14 and 21 ( $p$ values $<0.001,<0.001$, $<0.001$ and 0.008 ) respectively. Deformed neurons and glial cells in group 3 mice were significantly lower when compared to group 1 mice ( $\mathbf{p}$ values $\mathbf{0 . 0 0 1}$ ). GAP43 expression in group 3 mice was significantly higher when compared to group1 ( $p$ value $<0.001$ ). Deformed neurons in subgroup $3 b$ was significantly less than subgroup $3 a$ ( $\mathbf{p}$ value $<0.001$ ). GAP43 expression in group 3 mice was significantly increased when compared to group 2 mice ( $p$ value $<0.001$ ).

Conclusion: NOGO-A gene SiRNA is a potential enhancer of the neuro-regenerative action of MSCs.

\section{Introduction}

Amyotrophic Lateral Sclerosis is a progressive fatal neurodegenerative disease that targets motor neurons. Its origin is unknown but a main role of reactive astrogliosis and microglia activation in the pathogenesis had been demonstrated. Surrounding neurons with healthy adjoining cells completely stops motor neuron death in some cases. Hence stem cell transplantation might represent a promising therapeutic strategy [1].Neuronal regeneration in Central nervous system (CNS) is inhibited by Nogo- A; the best-studied myelin-associated inhibitory molecule. Acute inactivation by function-blocking antibodies or Nogo receptor antagonists, or blockade of the downstream signals RhoA or ROCK, enhances both regeneration of injured fibers tracts and compensatory sprouting of the spared corticospinal tract and other fibers [2]. 
MSCs present a promising tool for cell therapy. Extensive preclinical evidence for MSCs-based tissue regeneration is accumulating. Translational research for MSC-based regeneration is now under trial through numerous FDA-approved clinical trials for myocardial infarction, stroke, meniscus injury, limb ischemia, graft-versus-host disease and autoimmune disorders [3].

The aim of this work was to study the role of heterologus MSCs in neuro-regeneration and compare it to genetically modified MSCs transfected with a plasmid coding for NOGO gene silencing RNA in animal models with induced motor neuron degeneration.

\section{Materials And Methods}

This study was conducted in the tissue culture laboratory of the Clinical Pathology Department of Kasr Alainy Medical School. This work was funded by Cairo University.

Animals were used with full consideration of the ethical guidelines of animal research and the principles of Reduction, Replacement and Refinement [4].

Forty adult Albino mice weighing (115 \pm 5 grams) (age: 10-11 weeks) were used in this study. The animals were obtained from the Animal House Colony of Kasr Alainy Medical School, Cairo, Egypt

\section{The study group was divided as follows:}

- Donor group: 5 mice were used to obtain bone marrow for MSC isolation and expansion.

- Normal Control group: 10 mice were used as a normal control group.

- Motor neuron degeneration was induced in 30 mice and they were further divided into:

Group 1: 10 animal models with induced neuronal degeneration which received no therapeutic intervention.

Subgroup 1a: 5 mice, sacrificed 7 days after the removal of the neurodegenerative causative agent from the drinking water.

Subgroup 1b: 5 mice, sacrificed 14 days after the removal of the neurodegenerative causative agent from the drinking water.

Group 2:10 animal models with induced neuronal degeneration which received treatment through intravenous (tail vein) injection of a single dose of unmodified heterologus MSCs after the removal of the neurodegenerative causative agent from the drinking water.

Subgroup 2a: 5 mice, sacrificed 7 days after treatment.

Subgroup 2 b: 5 mice, sacrificed 14 days after treatment. 
Group 3: 10 animal models with induced neuronal degeneration which received treatement through intravenous (tail vein) injection of a single dose of the plasmid transfected heterologus MSCs after the removal of the neurodegenerative causative agent from the drinking water.

Subgroup 3a: 5 mice, sacrificed 7 days after treatment.

Subgroup 3b: 5 mice, sacrificed 14 days after treatment (Fig 1).

\section{Creation of Animal models of motor neuron degeneration}

This was achieved by oral administration of methyl mercury(MeHg), 30 parts per million (ppm) ( $1 \mathrm{ml}$ of nestler solution in $500 \mathrm{ml}$ of water and $500 \mathrm{ml}$ of methanol) dissolved in drinking water were administered for 8 weeks, and were given to groups 1,2 and 3 of the study group.

Animal model induction was verified by clinical assessment of the study group. Clinical assessment of the study group was done by following up the weight and range of movement. Assessment of motor power was done using a simple scoring scale developed to assess to the motor activity of the study group with a score from 0 to 5 as follows:

$0=$ lack of movement, $1=$ slight movement of tail, $2=$ slight movement of tail or limbs, $3=$ slight movement of tail and limbs, $4=$ whole body movement but restricted in place, $5=$ free movement across the cage.

Also the development of neuronal degeneration was verified by histological examination of post mortem sections from the cerebral cortex of rats which received the neurodegenerative drug and had no theraputic intervention.

\section{Isolation and Culture of Heterologus Murine Bone Marrow}

Bone marrow was obtained by flushing the mouse bones with phosphate buffered saline (PBS) and then cells were cultured, the culture media were prepared as follows: 500 cc Dulbecco's Modified Eagle Medium (DMEM) \# D5546 low glucose media supplemented by 55 cc (10\%) Fetal Bovine Serum \# F6178 and $5.5 \mathrm{cc}(1 \%)$ penicillin-streptomycin \# P4333 All procedures were done following the principles of sterile areas.

Cells were seeded in non-ventilated culture flasks at a density of $5 \times 10^{5}$ cells/ flask, covered with warm complete culture media and incubated at $37^{\circ} \mathrm{C} \& 5 \% \mathrm{CO}_{2}$.

\section{Selection and Propagation of Murine Mesenchymal Stem Cells.}

MSCs were selected by their adherence property, where non adherent cells were discarded and adherent cells when reaching $90-100 \%$ confluency were harvested and passaged. MSCs isolated from passage 3 were used in the study (fig2). 


\section{Identification for Lineage Commitment and Management of Harvested MSCs}

Harvested cells were assessed for their MSCs lineage commitment by morphological assessment and according to the minimal criteria for identification of MSCs [5] positive expression of the MSC markers (CD105 \& CD 90) and negative expression of the Stem cell marker (CD 34) (fig3).

After MSCs lineage purity was confirmed cells were divided into 2 groups; "Cells group 1" were non modified MSCs that were labeled with iron, where one hundred microns of ferrous oxide were added per $100 \mathrm{ml}$ of cultured cell suspension and incubated for 15 minutes immediately before the usage of the MSCs for treatment of animal models and "Cells group 2" were transfected with a plasmid coding for a NOGO gene silencer RNA that had an incorporated green fluorescent protein (GFP) fluorescent marker (Fig 4).

\section{Transfection of the Harvested MSCs}

The transfected Plasmid vector used was a commercially supplied lentiviral particle that contained coding areas for Mouse NOGO shRNA, a microRNA-adapted shRNA (based on miR-30) for NOGO gene (fig5).

For plasmid preparation, GIPZ shRNA clones were grown at $37^{\circ} \mathrm{C}$ in low salt broth medium (LB) plus 100 $\mu \mathrm{g} / \mathrm{mL}$ carbenicillin then plasmid DNA was isolated using the Plasmid DNA was isolated using Thermo Scientifi $^{\text {TM }}$ GeneJET $^{\text {TM }}$ Plasmid Miniprep Kit (Cat \#K0502) as per manufacturer s instructions.

The cultured MSCs were transfected using the Thermoscientific GiPZ mouse Lentiviral ShRNA transfection kit( \# RMM4532, UK) .

Transfection was done in a 6-well plate. In each well, $20 \times 10^{5}$ suspension cells were seeded in $4 \mathrm{~mL}$ of growth medium 24 hours prior to transfection, twenty-four $\mu \mathrm{g}$ of DNA were diluted in $2400 \mu \mathrm{L}$ of DMEM , TurboFect Transfection Reagent was briefly vortexed and $8 \mu \mathrm{L}$ were added to the diluted DNA and mixed immediately by pipetting. The mixture was incubated $15-20$ minutes at room temperature.

Four hundred $\mu \mathrm{L}$ of the TurboFect reagent/DNA mixture were added drop-wise to each well. The plates were gently rocked to achieve even distribution of the complexes. Plates were incubated at $37^{\circ} \mathrm{C}$ in a $\mathrm{CO} 2$ incubator, twenty-four hours later cells were started to be grown in selective medium.

Transgene expression was analyzed 24-48 hours later were cells were shown to exhibit green flouresence (fig 3c).

Selection of transfected cells was done through antibiotic resistance. Determining Antibiotic Dose Response (Kill Curve) was performed in order to determine the minimum amount of antibiotic required to kill non-transfected cells. 
The appropriate concentration for puromycin selection was determined based on kill curve was found to be $12 \mathrm{Ug} / \mathrm{ml}$ and it was used.

\section{Treatment of Animal Models}

Group 1: 5 mice were left as control and received no treatment, Group 2: 10 mice were inravenously injected with unmodified MSCs at a dose of $4.5 \times 10^{6}$ cells/ K.g ; an average 120 grams mouse received $5.6 \times 10^{6}$ cells, Group 3: 10 mice were intravenously injected with transfected MSCs at a dose of $4.5 \times 10^{6}$ cells/ $\mathrm{Kg}$; an average 120 grams mouse received $5.6 \times 10^{6}$ cells. Animals were sacrificed on 2 intervals; first subgroups $2 a$ and $3 a$ were sacrificed after 1 week from receiving the treatment then subgroups $2 b$ and $3 \mathrm{~b}$ were sacrificed after 2 weeks from receiving the treatment to study the effect of time on the degree of recovery.

\section{Assessment of Treated Animal Models}

Intervention that was done in the study group was followed-up by:

\section{A. Clinical assessment of neuronal regeneration}

Clinical assessment was done using repeated weight assessments as well as motor power assessment by the proposed scoring system mentioned before on days $0,6,14$ and 21 ; day 0 being the first day of giving the neurodegenerative reagent in drinking water.

\section{B. Histological examination and morphometric Studies}

The mice belonging to experimental subgroups and corresponding control mice were sacrificed by cervical dislocation, using IP injection of phenobarbitone sodium $(60 \mathrm{mg} / \mathrm{kg})$. Frontal lobe specimens were embedded into paraffin wax. Sections of $5 \mu \mathrm{m}$ thickness were prepared and subjected to the following studies:

Histological Study by Hematoxylin and eosin [6].

Histochemical Study using Prussian blue $(\mathrm{Pb})$ stain to demonstrate the injected unmodified BMMSCs labeled with ferrous oxide [7].

\section{Immunohistochemical Study:}

Anti-GAP43 which is considered to be crucial component of an effective regenerative response in the nervous system according to the method described by Noorden [8] and Korshunova and Mosevitsky [9].

\section{Morphometric Study}

Using Leica Qwin 500 (Cambridge, UK) LTD image analysis, assessment of the area of deformed neurons and that of glial cells in H\&E stained sections was performed using interactive measurements menu. The 
area \% of GAP43+ve immunoexpression was performed using binary mode. The measurements were done in 10 high power fields in control and experimental groups.

\section{E) Statistical Analysis}

Quantitative data were summarized as means and standard deviations and compared using one-way analysis-of-variance (ANOVA). Any significant ANOVA was followed by Bonferroni post-hoc test to detect which pairs of groups caused the significant difference. P-values $<0.05$ were considered statistically significant. Calculations were made on statistical package of social sciences (SPSS) software 16.

\section{Results}

\section{A. Clinical Assessment:}

1. Weight: There was a significant decrease in weight of group 1 mice when compared to the normal control group on days 6, 14 and 21 Table (1) (p values < 0.001 )

2. Motor Power: a significant deterioration of the motor power was observed in group 1 mice when compared to the normal control group on days 6,14 and 21 ( $p$ value $=\mathbf{0 . 0 0 1 , 0 . 0 0 1}$ and 0.008 ) respectively.

Table (1): Clinical assessment of the mean weight and motor score of group 1 mice on days; 6,14 and 21 in comparison to the normal control group

\begin{tabular}{|c|c|c|c|c|c|}
\hline & \multicolumn{2}{|c|}{ normal control * $(n=10)$} & \multicolumn{2}{|c|}{ Group $1 * *(n=10)$} & \multirow[t]{2}{*}{ p value ${ }^{\star \star \star}$} \\
\hline & Mean & SD & Mean & SD & \\
\hline Weight (grams) day 6 & 120.00 & 1.58 & 110.50 & 2.32 & $<0.001$ \\
\hline Weight (grams) day 14 & 119.80 & 2.17 & 106.30 & 2.26 & $<0.001$ \\
\hline Weight (grams) day 21 & 119.00 & 1.58 & 100.00 & 1.41 & $<0.001$ \\
\hline motor score day 6 & 5.00 & 0.00 & 0.90 & 0.74 & 0.001 \\
\hline motor score day 14 & 5.00 & 0.00 & 0.82 & 0.50 & 0.001 \\
\hline motor score day 21 & 5.00 & 0.00 & 0.60 & 0.89 & 0.008 \\
\hline
\end{tabular}

*Normal mice that received no drugs or intervention.

** Mice with induced neuronal degeneration receiving no therapeutic intervention.

***p value $<0.05$ is considered to be statistically significant

\section{Extent of Neuro-degeneration:}


In group 1 mice the mean area of deformed neurons was $0.75 \pm 0.19 \mu^{2}$ while no deformed neurons were found in the normal control group. The mean area of glial cells in group 1 was significantly higher than the normal control group $\left(0.68 \pm 0.12 \mu^{2} v s 0.39 \pm 0.05 \mu^{2}\right.$ respectively, $\mathbf{p}$ value $\left.<0.001\right)$. This indicates a successful induction of an animal model of motor neuron degeneration.

\section{Exent of Neuroregeneration:}

The mean area percentage of positive GAP43 expression in group 1 was significantly lower when compared to the normal control group $(0.41 \pm 0.15 \%$ vs $1.13 \pm 0.18 \%$ respectively, $\mathbf{p}$ value $<0.001)$ (fig6).

Comparing the mean weight and motor score of group 1on day 14 and on day 21 showed a statistically significant decrease in weight in subgroup $1 \mathrm{~b}(100.0 \pm 1.41 \mathrm{vs} 107.8 \pm 1.92 \mathrm{gm}$ respectively,p value $=$ 0.008) and no statistical improvement of motor power $(0.60 \pm 0.89$ vs $0.8 \pm 0.84$ respectively, $p$ value $=$ $0.69)$,

The mean area of deformed neurons in subgroup $1 \mathrm{~b}$ was significantly higher than subgroup $1 \mathrm{a}(\mathbf{0 . 9 1 \pm}$ 0.08 vs $0.58 \pm 0.09 \mu^{2}, p$ value $\left.<0.001\right)$ ( fig7)

Similarly the mean area of glial cells in subgroup $1 \mathrm{~b}$ was significantly higher than subgroup $1 \mathrm{a}(0.91 \pm$ 0.08 vs $0.58 \pm 0.09 \mu 2$ respectively,p value $<0.001$ ) indicating that removal of the neurodegenerative drug did not stop the weight loss, improve the motor function with time nor reverse the neuronal damage.

Also the mean area percentage of GAP 43 expression was significantly lower in subgroup $1 \mathrm{~b}$ when compared to subgroup 1 a $(0.28 \pm 0.04$ vs $0.54 \pm 0.10 \%$, p value $<0.001)$ (figure 8$)$.

There was a progressive significant increase in the weight of group 2 mice when compared to group 1 on days 14 and 21 ( $p$ values $<0.001$ ) and a significant increase in the motor scores ( $p$ value $=0.001 \& 0.026$ ) indicating a clinical improvement after unmodified MSCs treatment (Figure 9).

Also, the area of deformed neurons and mean area of glial cells in group 2 were both significantly lower compared to group 1 mice $\left(0.37 \pm 0.10 \mu^{2}\right.$ and $0.36 \pm 0.07 \mu^{2} v s \quad 0.36 \pm 20.07 \mu^{2}$ and $0.68 \pm 20.12 \mu^{2}$ respectively, $\mathbf{p}$ value $<0.001$ ), The mean area \% of positive GAP43 expression in group 2 mice was significantly higher than that in group 1 mice $(0.82 \pm 0.13 \%$ versus $0.41 \pm 0.15$ respectively, $p$ value $<0.001)$ indicating an enhanced neuro-regenerative response after unmodified MSCs treatment (figure 10).

The mean area of deformed neurons and mean area of glial cells in subgroup $2 \mathrm{~b}$ were significantly lower in comparison to subgroup 2 a $\left(0.31 \pm 0.06\right.$ and $0.35 \pm 0.08 \mu^{2} v s 0.43 \pm 0.09$ and $0.36 \pm 0.06 \mu^{2}$ respectively, $p$ values $=0.002$ and 0.03 ) indicating an improvement of response with time. Also the mean area \% of GAP43 expression in subgroup $2 b$ was significantly higher compared to subgroup $2 a(0.82 \pm 0.13$ vs 0.41 $\pm 0.15 \%$ respectively, p value $\mathbf{0} \mathbf{0 . 0 3 0}$ ) (figure 11 ).

The weight and motor score of group 3 mice on day 14 and 21 were compared to group 2 mice to evaluate the effect of the genetic modification of the injected MSCs in enhancing the neuro-regenerative 
process but no significant changes were observed (table 2)

Table (2): Clinical assessment of the mean weight and mobility score of group 3 mice on days 14 and 21 in comparison to group 2

\begin{tabular}{|llllll|}
\hline & \multicolumn{2}{c}{ Group $2 *(n=10)$} & \multicolumn{2}{c|}{ Group 3**(n=10) } & \multirow{2}{*}{ p value*** } \\
\cline { 1 - 5 } & Mean & SD & Mean & SD & \\
\cline { 1 - 5 } Weight (grams) day 14 & 113.7 & 2.16 & 114.1 & 2.13 & 1 \\
\hline Weight (grams) day 21 & 117.20 & 1.64 & 117.4 & 2.30 & 1 \\
\hline motor score day 14 & 3.60 & 0.52 & 3.80 & 0.63 & 1 \\
\hline motor score day 21 & 4.60 & 0.55 & 4.80 & 0.45 & 1 \\
\hline
\end{tabular}

* Mice with induced neuronal degeneration treated with non-modified MSCs.

** Mice with induced neuronal degeneration treated with modified MSCs.

***p value $<0.05$ is considered to be statistically significant.

The mean area of deformed neurons and the mean area of glial cells of group 3 mice were not significantly different compared to group 2 mice $\left(0.22 \pm 0.09\right.$ and $0.37 \pm 0.10 \mu^{2} v s 0.33 \pm 0.06$ and $0.36 \pm$ $0.07 \mu^{2}$ respectively, $P=1$ ). But the mean area percentage of positive GAP43 expression in group 3 mice was significantly increased when compared to group 2 mice $1.04 \pm 0.11$ vs $0.82 \pm 0.13 \%$ respectively ,p value $\mathbf{0 . 0 0 1}$ ) (figure 12), indicating an enhanced neuro-regenerative process with transfected MSCs treatment compared to the unmodified MSCs treatment.

The motor power significantly improved on day 21 when compared to day 14 ( $4.8 \pm 0.45$ versus 3.60 $\pm 0.55, p$ value 0.016$)$ as well as the mean area of deformed neurons $\left(0.15 \pm 0.04\right.$ versus $0.29 \pm 0.05 \mu^{2}, p$ value $<0.001$ ) indicating an improvement of response with time (figure 13).

\section{Discussion}

In contrast to peripheral nerves, central nervous system injury is not followed by regeneration as it is limited by inhibitory mechanisms of glial regeneration and the non permissive microenvironment [10].

NOGO - The protein family Nogo, particularly, has been identified as an inhibitor of remyelination in the CNS, especially in autoimmune mediated demyelination, such as found in Experimental Autoimmune Encephalomyelitis (EAE) and Multiple Sclerosis (MS). Nogo A functions via either its amino-Nogo terminus through an unknown receptor, or by its Nogo-66 terminus through NgR1. Antagonising this inhibitor results in improved remyelination, as it is involved in the RhoA pathway [11]. 
MSCs are likely contribute to neurogenesis by inducing the secretion of different neurotrophic factors either directly from local precursors or indirectly from nearby activated astrocytes [12].

In the present work we demonstrated that treatment of animal models with induced motor neuron degeneration using MSCs transfected with a NOGO-A SiRNA coding gene resulted in an enhanced histopathological recovery in terms of decrease in the mean area of degenerated neurons, decrease in the mean area of glial cells and increase in the GAP43 "marker of neuro-regeneration" expression with subsequent improvement in weight and motor power over time.

NogoA gene RNAi is an effective method for convenient and permanent NogoA gene silencing [13].

The goal of this study was to develop a therapeutic strategy that promotes functional recovery with minimal adverse affects and to add a complementary element to enhance the neuronal regenerating action of the MSCs.

In the present study, motor neuron degeneration was induced in 30 mice, 10 of which received no form of treatment, 10 were injected with unmodified MSCs and 10 were injected with plasmid transfected MSCs, while 10 mice were used as normal controls. All animals with induced motor neuron degeneration were sacrificed on 2 consecutive events; 7 and 14 days following the stoppage of the neurodegenerative drug and accordingly were further subdivided into subgroups $a$ and $b$ respectively.

Observation of group 1 mice showed verification of the motor degeneration model in the form of a significant reduction in weight and motor power when compared to the control group, the cerebral cortex revealed changes indicating cortical neuronal degenerative changes induced by the neurotoxic effect of MeHg. In subgroup $1 b$ the weight reduction was significantly lower than subgroup 1 a however there was no significant change in the motor power between the 2 subgroups, in group $1 \mathrm{~b}$ the cortical degenerative changes increased and the mean area of degenerated neurons was significantly increased in comparison to other groups. Obvious glial cells proliferation was noted and confirmed by significant increase in the area of glial cells in comparison to the control group, group2 and group 3.

Reactive gliosis that occurs in response to the CNS injury leads to volume expansion, proliferation and starting inflammatory pathways and thus it isolates the damaged area by forming a glial scar. This phenomenon has short and medium term benefits, because it limits the area of injury and contains the inflammatory process. Thus, it is a key mediator of the neuronal metabolic processes in different physiological, toxic and neurodegenerative reactions [14].

The glial cells have an increased ability to accumulate $\mathrm{MeHg}$ compared to the neurons, this alters their cell cycle and increase their proliferation [15]. Gliosis results in beneficial and injurious effects that balance each other. From the benefits of gliosis is the development of an adaptive mechanism that provides trophic support and sustains homeostasis that is required for neuronal survival under $\mathrm{mild} /$ moderate insults [16]. 
Using GAP43 immuno stain as a marker of neuronal regeneration, the cerebral cortex of control rats showed obvious +ve immunoexpression (IE) of GAP43 in the pyramidal neurons and neuropil. In group 1, the positive IE was noted in few neurons and was less obvious among the neuropil. This was proved by a significant decreased in the area \% of GAP43 IE in comparison to control group indicating the neuronal degeneration and axonal destructions.

GAP43 is a signaling molecules of the neurons involved with neuronal growth, synaptic transmission and plasticity [17]. Although it presents along the whole neuron it is present in higher levels in axon terminals and growth cones where it acts to regulate the actin dynamics. It is a useful marker of neuronal regeneration and a reduction in its expression indicates an impairment of neuronal regeneration and viability [17].

The mice of group 2 which were treated with unmodified MSCs showed a significant improvement in weight and motor power compared to untreated mouse models. Regarding the histological recovery they possessed less degenerative changes in their cerebral cortex and demonstrated a statistical significant increase in evidence of neural regeneration confirmed by the decrease in the mean area of deformed neurons and glial cells and the increase in the area percentage of positive GAP43 expression in comparison to group 1 mice, this indicates the formation of new synapses, neurite outgrowth and synaptogenesis after injury. In accordance with Zhang et al., [18] GAP43 is implicated in axonal plasticity and regeneration.

The use of regenerative medicine in management of diseases of the brain is becoming increasingly promising. MSCs are known with their potential to differentiate into multiple cell lineages including a neuronal cell line [19]. The use of MSCs has improved the functional outcomes in different CNS pathologies including spinal cord injury [20] ischemic brain stroke and epilepsy [21].

In 2013 a phase I/II controlled single-blind clinical trial was conducted on Egyptian patients with chronic spinal cord lesions, where they were treated with either intrathecal injection(s) of autologous adherent bone marrow cells in addition to physical therapy in or managed only with physical therapy. When autologous adherent bone marrow cell therapy was combined with physical therapy it appeared to be a safe and promising therapy for patients with chronic spinal cord lesions of traumatic origin [22].

It has been postulated that stem cells produce their effect through multiple pathways. They are able to suppress inflammation and alter the immune response in the CNS through their effect on the behavior of microglial cells by inhibiting microglial proliferation and inhibiting them from releasing pro-inflammatory molecules and by increasing their phagocytic capacity through the release of soluble factors [23]. SCs have an inhibitory effect on nuclear factor-Kappa B which is a key protein complex that is involved in the inflammatory and apoptotic cascades [24].

MSCs were proven to secrete fractions of microvesicles that produce a high regenerative effect on the injured brain. The extracts of those microvesicles have neuroprotective properties [25] and enhance neuronal regeneration [26]. 
The mice which were treated with MSCs transfected with a NOGO-A Si RNA coding gene showed a significant clinical improvement regarding weight gain and increase in motor power when compared to the untreated group however no significant difference was observed when clinically compared with group 2. Improvement in motor score was significantly better in subgroup $3 \mathrm{~b}$ compared to subgroup $3 \mathrm{a}$ indicating the enhance effect of the transfected MSCs with time.

More enhanced histological recovery in terms of a decrease in mean area of glial cells and deformed neurons was observed in group3 compared to the untreated mice however the difference when compared to mice receiving genetically non modified cells was not statistically significant. Subgroup 3b mice had a significant reduction in the mean area of deformed neurons compared to subgroup 3a.

Group 3 had a significantly higher expression of the GAP43 marker of neuronal regeneration when compared to mice treated with non modified MSCs.

In accordance with our results Grand Pre et al., [27] first identified a Nogo-66 (1-40) competitive antagonist peptide (NEP1-40) and found that the NEP1-40 intrathecal administration significantly induced axonal growth in the cortico-spinal tract and improved functional recovery following midthorathic spinal cord hemisection in rats.

Another study to demonstrate that siRNA directed toward axonal inhibitors expressed in the CNS is a promising therapeutic option for promoting functional recovery was carried out by Yang et al., [28]. The study found that intravenous administration of a Nogo-A siRNA in mice with experimental autoimmune encephalomyelitis (EAE) improved their functional capacity and was associated with decreased NogoAexpression. In addition, GAP43, a marker of neural regeneration, was remarkably up regulated suggesting that axonal repair in the siRNA-NogoA treated mice may be responsible for the improved clinical outcome.

Zhao et al., [29] examined the results of Nogo-A suppression on the development of oligodendrocytes in cell culture. The siRNA mediated Nogo-A silencing in these oligodendrocytes did not alter their rate of proliferation but knockdown of the expression of Nogo-A significantly enhanced the process branching complexity. They suggested that although Nogo-A silencing in the purified oligodendrocyte cultures had no effect on their proliferation rate and the expression level of mature oligodendrocytes markers; the absence of Nogo-A resulted in faster polarization and enhancement of the branching processes, which is an important event for initiation of myelination.

The in-vitro effect of siRNAs against Nogo receptor on neurite outgrowth under an inhibitory substrate of CNS myelin was investigated in a study which demonstrated that knockdown of Nogo receptor can improve neurite outgrowth [13].

In agreement with our study a recent study hypothesized that RNA interference to silence Nogo-66 receptor gene expression in bone marrow mesenchymal stem cells before transplantation might further improve neurological function in rats with spinal cord transection injury, the study showed that 
mesenchymal stem cell transplantation, after Nogo-66 receptor gene silencing, is greatly superior to simple mesenchymal stem cell transplantation in the treatment of spinal cord injury in rats, in terms of histological and functional outcomes also tissue repair was better in the Nogo- 66 receptor gene silencing group compared with the model and bone marrow mesenchymal stem cell groups [30].

Our study showed that the mice in both treated groups demonstrated progressive improvement over time, the mice treated with unmodified MSCs showed a statistically significant improvement of weight and motor power. Histological recovery was significant in terms of decrease in area of deformed neurons and glial cells and increase in GAP43 expression. The mice treated with the plasmid transfected MSCs had a non-significant increase in weight over time but the improvement of motor power with time was statistically significant, regarding the histological recovery there was a statistically significant decrease in the area of deformed neurons with time however the decrease in area of glial cells and the increase in the area percentage of positive GAP43 expression did not reach the level of statistical significance.

This emphasizes the importance of using a permanent method for the NOGO A gene knock down rather than the injection of monoclonal antibodies and peptide inhibitors which may be neutralized by the development of antibodies or degraded.

As a conclusion, our study agrees with the previous studies to emphasize the role of adding NOGO A gene inhibition to achieve better neuronal regeneration, enhanced neuronal branching and according to our study a better clinical outcome in treatment of neural disorders when compared to the sole use of unmodified MSCs.

To our best knowledge, this is the first study to use NOGO A gene Si RNA as a means of NOGO A gene inhibition as well as being carried in vivo as an animal based experimental study in models of neurodegeneration.

Currently, only two approved medications, riluzole and edavarone has been shown to have a modest effect on survival of patients with ALS. Thus, there remains a high unmet medical need to identify new treatment options for patients with ALS. In 2017 Meininger et al., reported the results of a large, randomised, placebo-controlled, phase 2 trial of ozanezumab, a monoclonal antibody against neurite outgrowth inhibitor A (Nogo-A) in ALS, although negative results were obtained, The lack of efficacy in this study indicates the need of an alternative method of NOGO A inhibition [31].

A longer study would be of great benefit to study better the effect of time on the permanent NOGO A gene silencing as well as investigate the possibility of development of any related behavioral changes.

Also performing the study on a larger scale is recommended to increase the credibility of data and prepare the modified stem cell therapy to move into the second phase of clinical trials.

\section{List Of Abbreviations}


- 3' SIN LTR: 3' self-inactivating long terminal repeat

- 5' LTR: 5' long terminal repeat

- ALS: Amyotrophic Lateral Sclerosis

- CNS: Central nervous system

- DMEM: Dulbecco's Modified Eagle Medium

- EAE: Experimental Autoimmune Encephalomyelitis

- GFP: green fluorescent protein

- hCMV: Human cytomegalovirus

- IE: immunoexpression

- IRES: Internal ribosomal entry site

- LB: low salt

- MeHg: Methyl mercury

- MSCs: Mesenchymal stem cells

- Pb: Prussian blue

- PBS: Phosphate buffered saline

- ppm: Parts per million

- PuroR: Puromycin resistance

- RRE: Rev response element

- SPSS: Statistical package of social sciences

- tGFP: TurboGFP reporter

- WPRE: Woodchuck hepatitis posttranscriptional regulatory element.

- $\Psi$ : Psi packaging sequence

\section{Declarations}

\section{Ethical Approval and Consent to participate}

Animals were used with full consideration of the ethical guidelines of animal research and the principles of Reduction, Replacement and Refinement, this work have been approved by the department of chemical and clinical pathology, Cairo University.

\section{Consent for publication}

This article doesn't include information or images that could lead to identification of a study participant.

Availability of supporting data 
The datasets used and/or analyzed during the current study are available from the corresponding author on reasonable request.

\section{Competing interests}

The authors declare no competing interests.

\section{Funding}

This wrok has been funded by Kasr Al Ainy medical school.

\section{Authors' contributions}

Hala Gabr: Presented the research idea, supervision of the practical work and manuscript revision.

Nirmeen A Kishk: Clinical follow up and evaluation of the study groups and manuscript revision.

Maha Baligh Zickri: Histological examination of the tissue sections and morphometric studies of all sacrificed groups.

Shahira KA Botros: Supervision of the practical work , manuscript writing and statistical analysis.

Amal S. Ashour: Clinical follow up and evaluation of the study groups.

Eman A. Youssef: Conduction of the experiment and manuscript submission.

\section{Acknowledgements}

The authors would like to thank "Kasr alainy Medical School" for contributing financially to this work also we acknowledge all personals working in Kasr alainy animal house and cell culture laboratories.

\section{References}

1. Mazzini L, Mareschi K, Ferrero I, Vassallo E, Oliveri G, Nasuelli N, et al. Stem cell treatment in amyotrophic lateral sclerosis. J Neurol Sci 2008; 265(1):78-83.

2. Guzik-Kornacka AM, Vajda F, Schwab ME. Blocking the Nogo-A Signaling Pathway to Promote Regeneration and Plasticity After Spinal Cord Injury and Stroke. In: Tuszynski M, editors. Translational Neuroscience. Springer: Boston: MA; 2016. 369-397.

3. Squillaro T, Peluso G, Galderisi U. Clinical Trials with Mesenchymal Stem Cells: An Update . Cell Transplant 2016;25(5):829-48.

4. Flecknell P. Replacement, reduction and refinement. ALTEX 2002;19(2):73-8.

5. Dominici, M. L. B. K., K. Le Blanc, I. Mueller, I. Slaper-Cortenbach, F. C. Marini, D. S. Krause, R. J. Deans, A. Keating, D. J. Prockop, and E. M. Horwitz. "Minimal criteria for defining multipotent 
mesenchymal stromal cells. The International Society for Cellular Therapy position statement." Cytotherapy8, no. 4 (2006): 315-317.

6. Kiernan Histological and Histochemical methods: Theory and Practice, $3^{\text {rd }}$ ed. Arnold publisher; London, New York \& New Delhi: 2001.p. 111-162.

7. Ellis R. Perls Prussian blue Stain Protocol, Pathology Division, Queen Elizabeth Hospital: South Australia. 2007.

8. Noorden S. Principles of immunostaining. In: Histochemistry in pathology. Churchill Livingstone; Edinburgh: 1990. p. 31.

9. Korshunova I,Novitskaya V, Kiryushko D, Pedersen N, Kolkova K, Kropotova E, et al. GAP-43 regulates NCAM-180-mediated neurite outgrowth. J Neuroch. 2007; 100(6):1599-612.

10. Fernandes M, Valente SG, Sabongi RG, Gomes Dos Santos JB, Leite VM, Ulrich H, et al. Bone marrowderived mesenchymal stem cells versus adipose-derived mesenchymal stem cells for peripheral nerve regeneration. Neural Regen Res 2018;13 (1):100-104.

11. Yiu G, He Z. "Glial inhibition of CNS axon regeneration". Nat Rev Neurosci 2006; 7 (8):617-27.

12. Uccelli A, Moretta L, Pistoia V. Mesenchymal stem cells in health and disease. Nat Rev Immunol 2008;8(9):726-36.

13. Ding SH, Bao YH, Shen JH, Gao GY, Pan YH, Luo QZ, et al. Improved neurite outgrowth on central nervous system myelin substrate by siRNA-mediated knockdown of Nogo receptor. Chin J Traumatol 2016;19 (1):16-24.

14. Leonoudaki D, Rane A, Angeli S, Lithgow GJ, Andersen JK, Chinta SJ. "Anti-inflammatory and neuroprotective role of natural product securinine in activated glial cells: Implications for parkinson's disease." Mediators Inflamm 2017; 2017: 8302636.

15. Pereira S, Pinto A, Alves V, Silva CA. "Brain tumor segmentation using convolutional neural networks in MRI images." IEEE Trans Med Imaging 2016;35 (5): 1240-1251.

16. Rosa PM, Martins LAM, Souza DO, and Quincozes-Santos A. "Glioprotective effect of resveratrol: An emerging therapeutic role for oligodendroglial cells." Mol Neurobiol 2018;55(4): 2967-2978.

17. Ceber M, Sener U, Mihmanli A, Kilic U, Topcu B, Karakas M. "The relationship between changes in the expression of growth associated protein-43 and functional recovery of the injured inferior alveolar nerve following transection without repair in adult rats." J Craniomaxillofac Surgery 2015; 43 (9): 1906-13.

18. Zhang L, Yue Y, Ouyang M, Liu H, Li Z. "The effects of IGF-1 on TNF-a-treated DRG neurons by modulating ATF3 and GAP-43 expression via PI3K/Akt/S6K signaling pathway." Neurochem Res 2017; 42 (5): 1403-1421.

19. Moradian H, Keshvari H, Fasehee H, Dinarvand R, Faghihi S. "Combining NT3-overexpressing MSCs and PLGA microcarriers for brain tissue engineering: a potential tool for treatment of Parkinson's disease." Mater Sci Eng C Mater Biol Appl 2017; 76: 934-943. 
20. Shende P, Subedi M. "Pathophysiology, mechanisms and applications of mesenchymal stem cells for the treatment of spinal cord injury." Biomed Pharmacother 2017; 91: 693-706.

21. Zhou L Lin Q, Wang P, Yao L, Leong K, Tan Z, et "Enhanced neuroprotective efficacy of bone marrow mesenchymal stem cells co-overexpressing BDNF and VEGF in a rat model of cardiac arrest-induced global cerebral ischemia." Cell Death Dis 2017; 8 (5): e2774.

22. El-Kheir WA, Gabr H, Awad MR, Ghannam O, Barakat Y, Farghali HA, et al.. Autologous bone marrowderived cell therapy combined with physical therapy induces functional improvement in chronic spinal cord injury patients. Cell Transplant 2014 ;23(6):729-45.

23. Xu C, Fu F, Li X, Zhang S. "Mesenchymal stem cells maintain the microenvironment of central nervous system by regulating the polarization of macrophages/microglia after traumatic brain injury." Int J Neurosci 2017; 127 (12): 1124-1135.

24. Yang T, Wang Y, Jiang S, Liu Z, Yu Z. "Hepatocyte growth factor-induced differentiation of bone mesenchymal stem cells toward hepatocyte-like cells occurs through nuclear factor-kappa B signaling in vitro." Cell Biol Int 2016;40 (9): 1017-23.

25. Baulch JE, Acharya MM, Allen BD, Ru N, Chmielewski NN, Martirosian V, et al. "Cranial grafting of stem cell-derived microvesicles improves cognition and reduces neuropathology in the irradiated brain." Proc Nati Acad Sci USA 2016;113 (17): 4836-41.

26. Bruno S, Tapparo M, Collino F, Chiabotto G, Deregibus MC, Lindoso RS, et al. "Renal regenerative potential of different extracellular vesicle populations derived from bone marrow mesenchymal stromal cells." Tissue Eng Part A 2017;23(21-22 ): 1262-1273.

27. Grandpre' T, Li S, Strittmatter SM. Nogo-66 receptor antagonist peptide promotes axonal regeneration. Nature 2002; 417(6888):547-551.

28. Yang Y, Liu Y, Wei P, Peng H, Winger R, Hussain RZ, et al. Silencing Nogo-A promotes functional recovery in demyelinating disease. Ann Neurol 2010; 67(4):498-507.

29. Zhao X, Wu J, Kuang F, Wang J, Ju G. Silencing of Nogo-A in rat oligodendrocyte cultures enhances process branching. Neurosci Lett 2011;499(1):32-36.

30. Li Z, Zhang Z, Zhao L, Li H, Wang S, Shen Y. Bone marrow mesenchymal stem cells with Nogo-66 receptor gene silencing for repair of spinal cord injury. Neural Regen Res. 2014;9(8):806-14.

31. Meininger V, Genge A, van den Berg LH, Robberecht W, Ludolph A, Chio A, et al. Safety and efficacy of ozanezumab in patients with amyotrophic lateral sclerosis: a randomised, double-blind, placebocontrolled, phase 2 trial. Lancet Neurol 2017;16: 208 - 216

\section{Figures}




\section{5 mice}

5 used to obtain BM
10 normal control group

\section{0 recieved neuro-degenrative agent for 6 days}

10 recieved no treatment (group1)

20 recieved a single dose of cells after stopping the neuro-degenrative agent

5 scrificed on day 14

(Subgroup 1a)

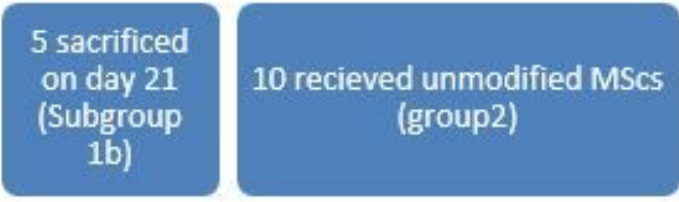

5 sacrificed on day 21 (Subgroup 1b)
10 recieved plasmid transfected MScs (group3)

5 sacrificed on day 14

(Subgroup 2a)
5 sacrificed on day 21

(Subgroup 2b)
5 sacrificed on day 14

(Subgroup 3a)
5 sacrificed on day 21

(Subgroup 3b)

\section{Figure 1}

Diagrammatic representation of the different groups and subgroups of the study. 


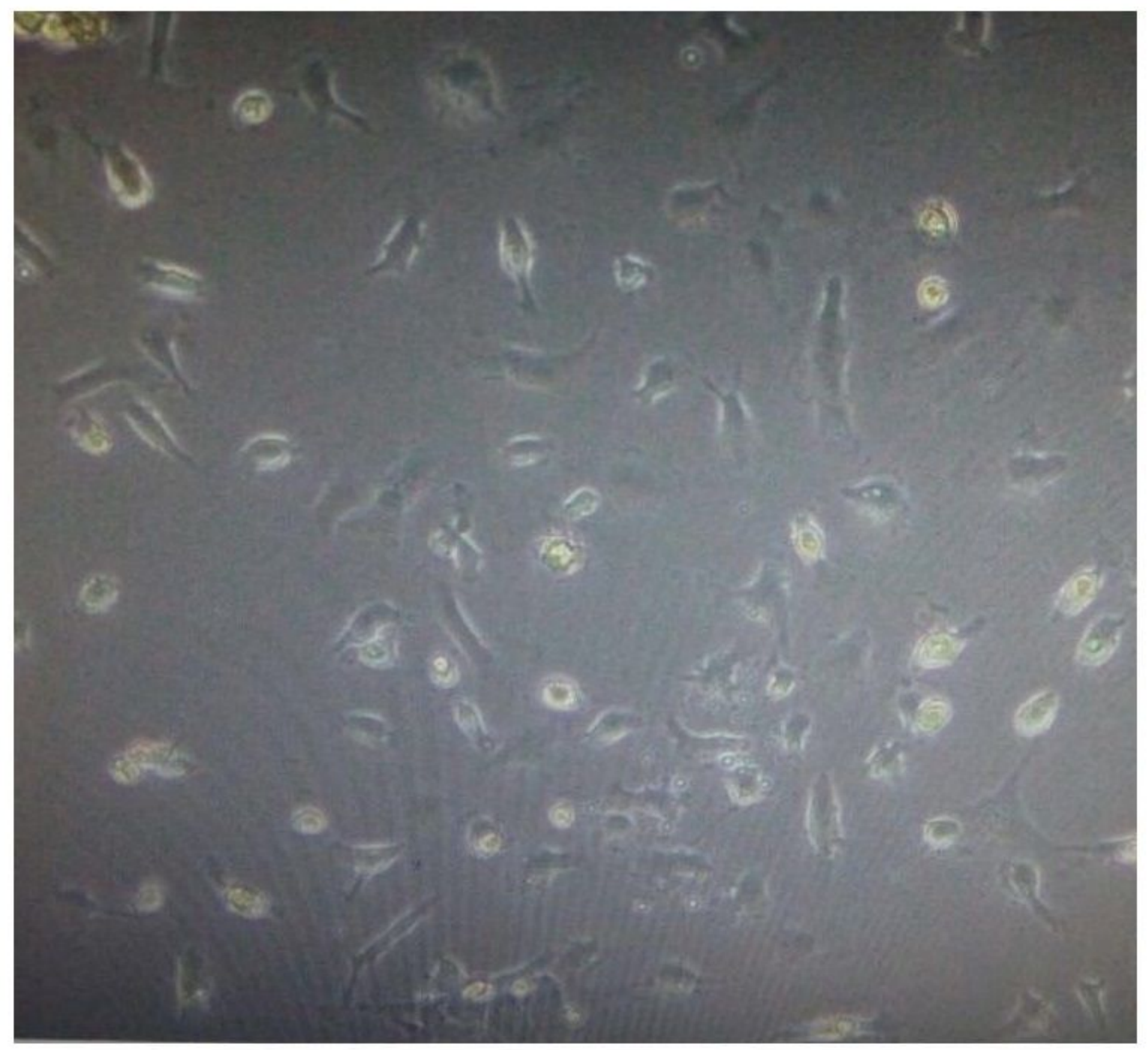

Figure 2

Mesenchymal stem cells, passage 1, 60\% confluence (200x) 

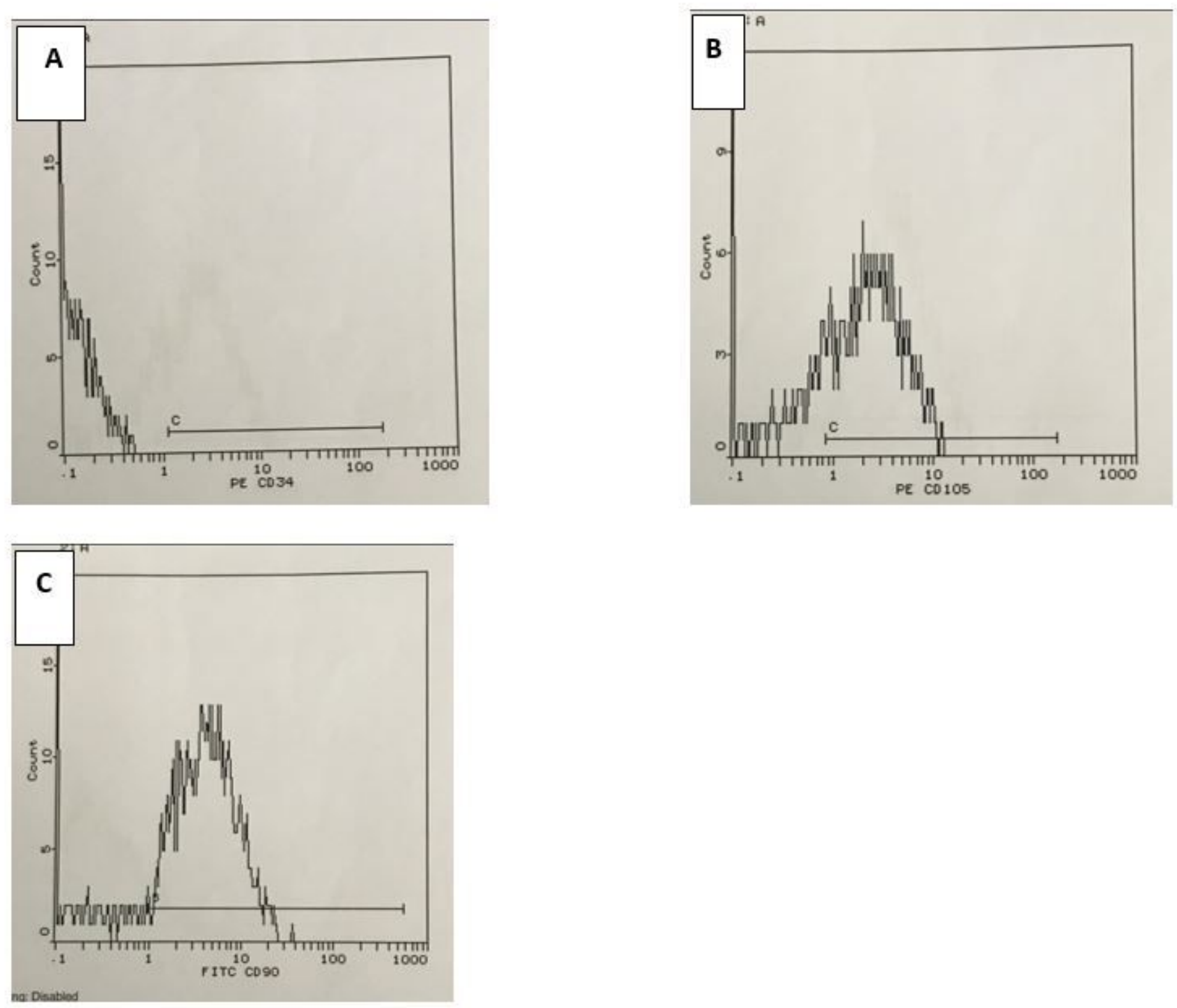

Figure 3

Histogram for flow cytomtery performed on the isolated MSCs showing (A) Negative expression of CD34 (0.11\%) (B) Positive expression of CD 105 (57.5\%) (C) Positive expression of CD 90 (77.1\%) 

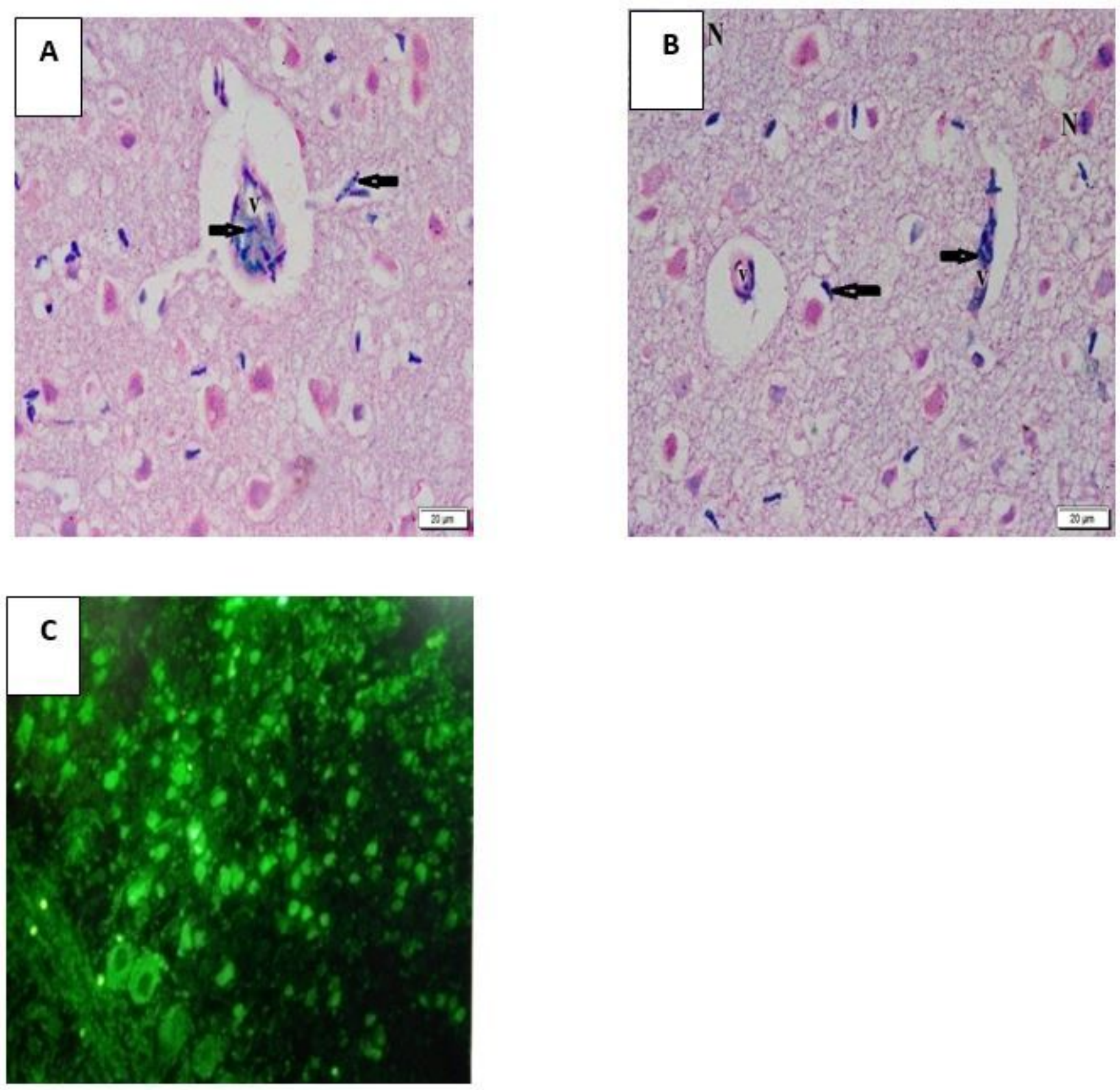

\section{Figure 4}

Sections of the cerebral cortex showing homing of the injected MSCs (A) Prussian blue stained sections of the cerebral cortex with multiple Prussian blue $(\mathrm{pb})$ positive cells $(\uparrow)$ in a vessel $(\mathrm{v})$ and in the neuropil. (x400) following injection of non-modified MSCs in subgroup 2a (B) fewer Prussian blue (pb) positive cells $(\uparrow)$ in a vessel $(v)$, in the neuropil and overlying neurons $(N)$. (x400) following injection of nonmodified MSCs in subgroup 2b. (C) Fluorescent microscopic image of sections of cerebral cortex after injection of transfected MSCs with plasmid containing GFP coding gene. 


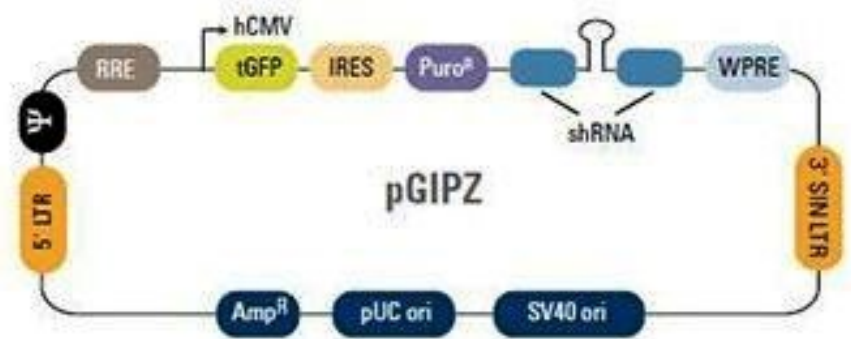

Figure 5

GIPZ Lentiviral vector Diagrammatic representation for different areas of the plasmid used for transfection of group2 MSCs, hCMV: Human cytomegalovirus promoter , tGFP: TurboGFP reporter, PuroR: Puromycin resistance, IRES: Internal ribosomal entry site, Mouse NOGO shRNA: microRNA-adapted shRNA (based on miR-30) for NOGO gene knockdown, 5' LTR: 5' long terminal repeat, 3' SIN LTR: 3' selfinactivating long terminal repeat, $\Psi$ : Psi packaging sequence, RRE: Rev response element \& WPRE: Woodchuck hepatitis posttranscriptional regulatory element. 

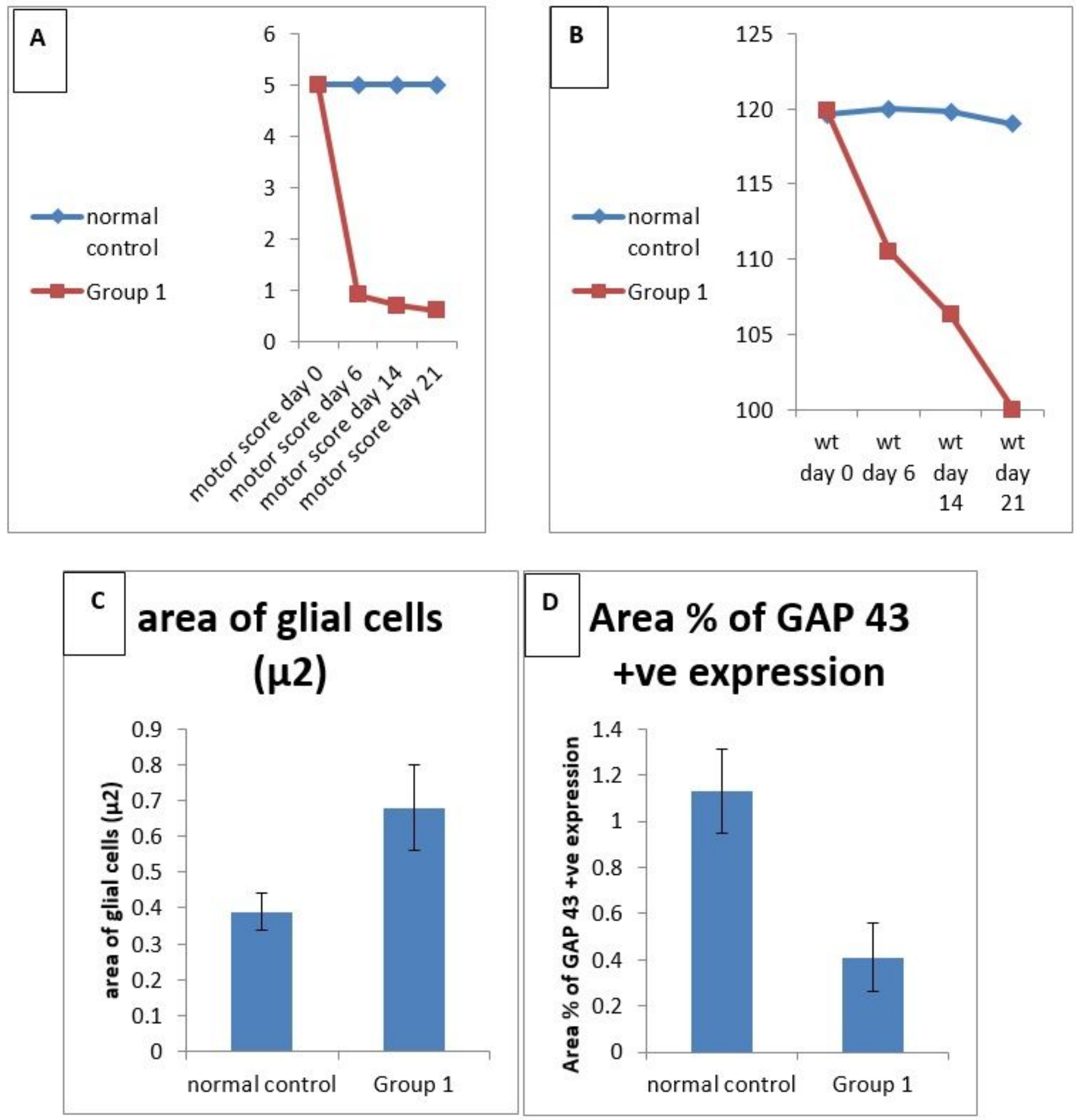

Figure 6

Graphic representation of $(A)$ the mean weight and (B) motor power of group 1 mice on days; 6,14 and 21 in comparison to the normal control group . (C) the mean area of deformed neurons in group 1 in comparison to the normal control group(D) Immunohistochemical study of positive GAP 43 expression in group 1in comparison with the normal control group Group1: Mice with induced neuronal degeneration receiving no therapeutic intervention. Normal control: Normal mice that received no drugs or intervention. 


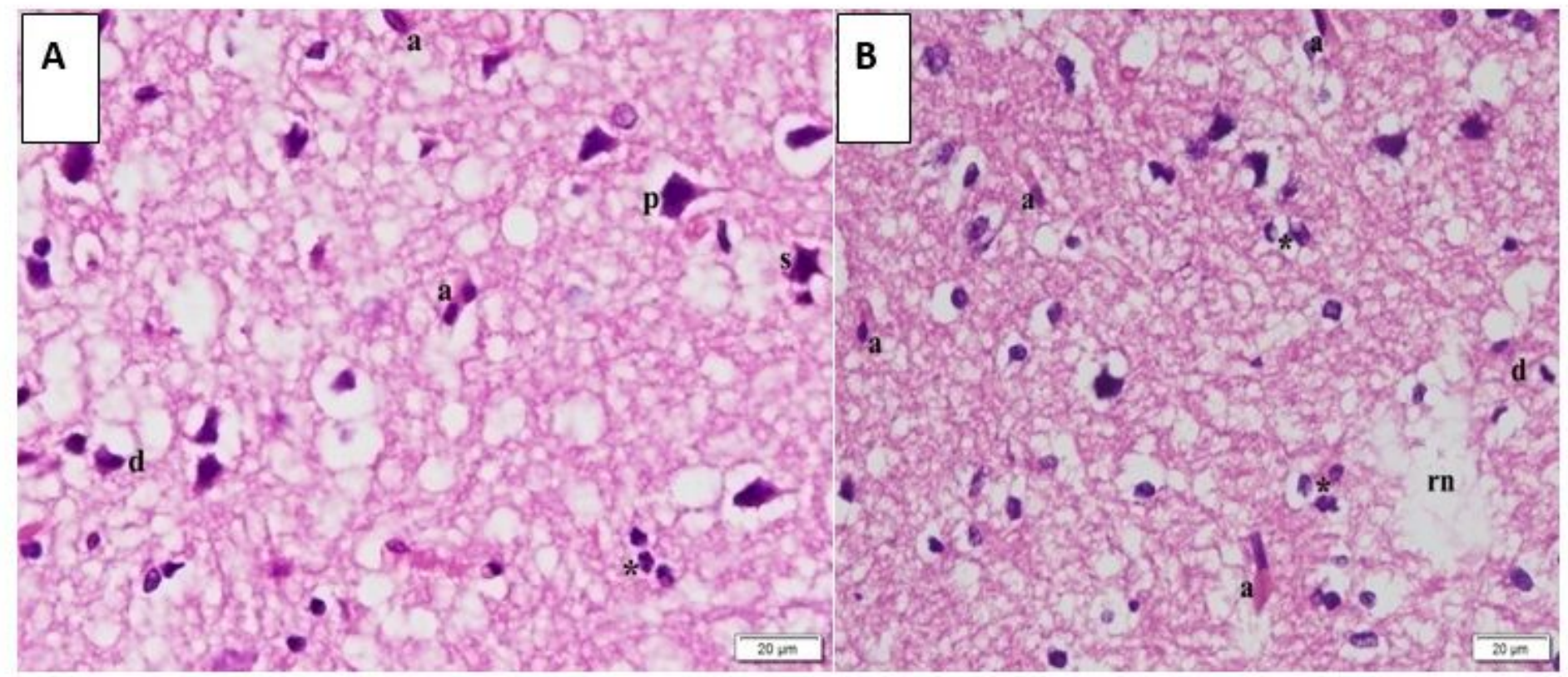

Figure 7

(A) Subgroup 1a (d): some deformed neurons, (a): few neurons with acidophilic cytoplasm and dark nuclei, $\left(^{*}\right)$ : glial cells proliferation, $(P)$ : few pyramidal and stellate neurons (H\&E, $\left.x 400\right)$. (B)Subgroup 1b (a): multiple neurons with acidophilic cytoplasm and dark nuclei, (d): some deformed neurons, $(\mathrm{rn})$ : obvious rarified neuropuil, (*): obvious glial cells proliferation (H\&E, x400).
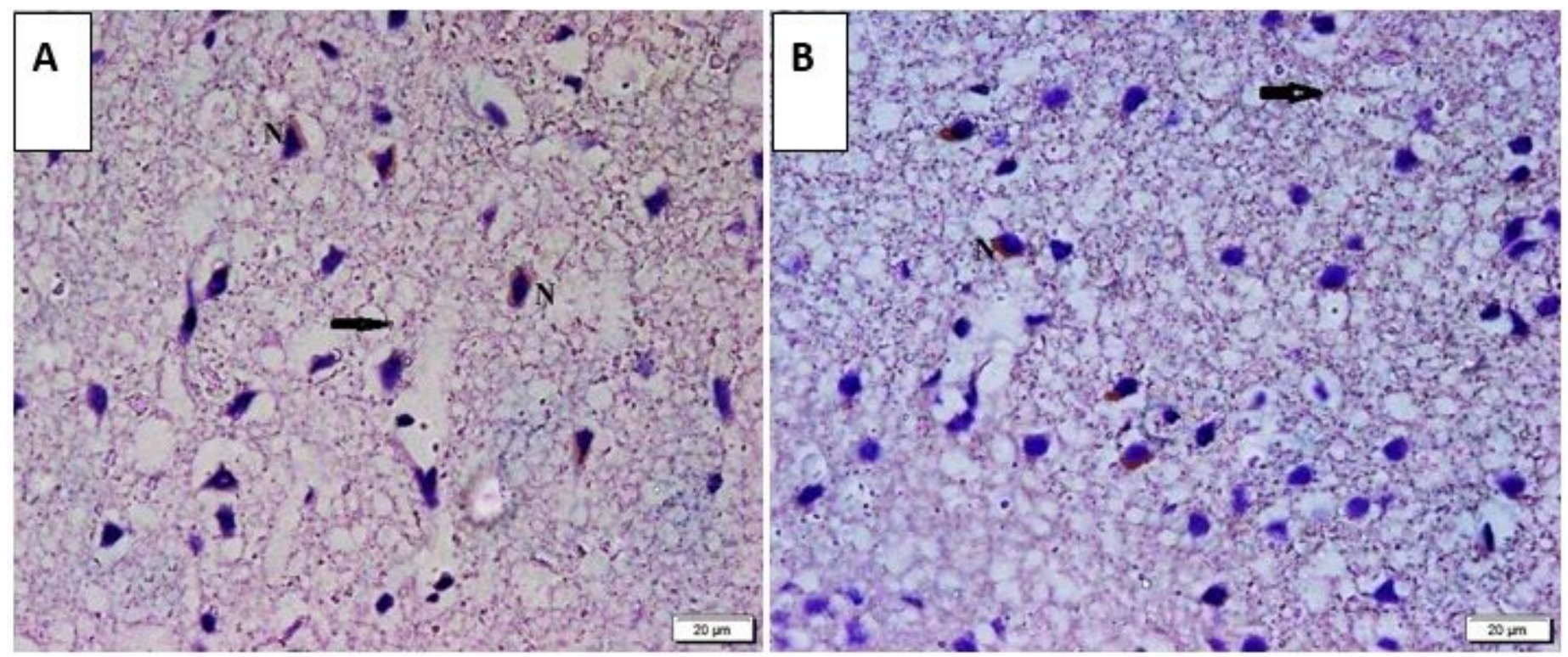

Subgroup 1a

\section{Subgroup 1b}

Figure 8 
(A) Subgroup 1 a: Positive GAP43 IE in few neurons (N) and less obvious IE among the neuropil (x400).

(B) Subgroup 1b , Minimal GAP43 IE (x400).

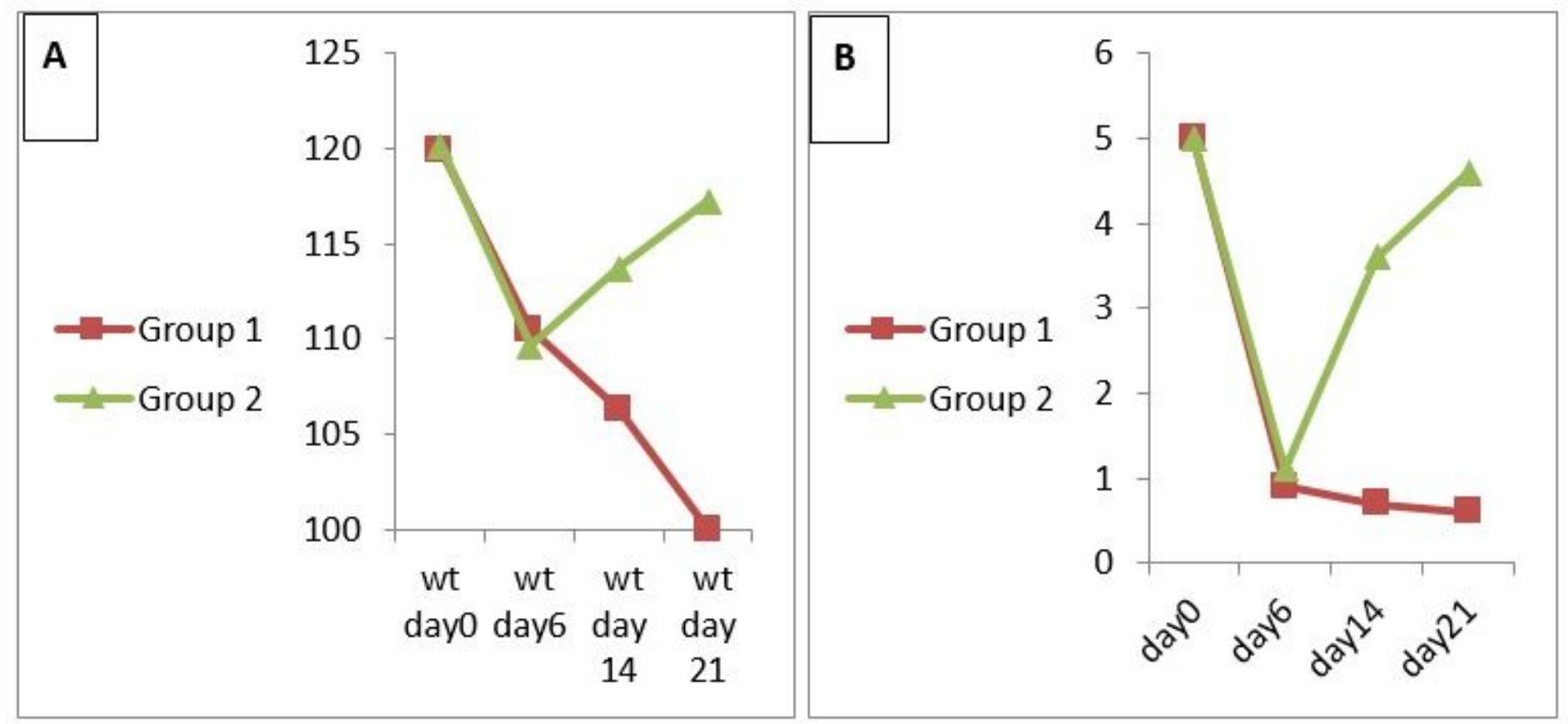

Figure 9

Graphic representation of (A)the mean weight (B) motor power, of group 2 mice on days 14 and 21 in comparison to group1 Group 1: Mice with induced neuronal degeneration receiving no therapeutic intervention. Group 2: Mice with induced neuronal degeneration treated with non-modified MSCs.
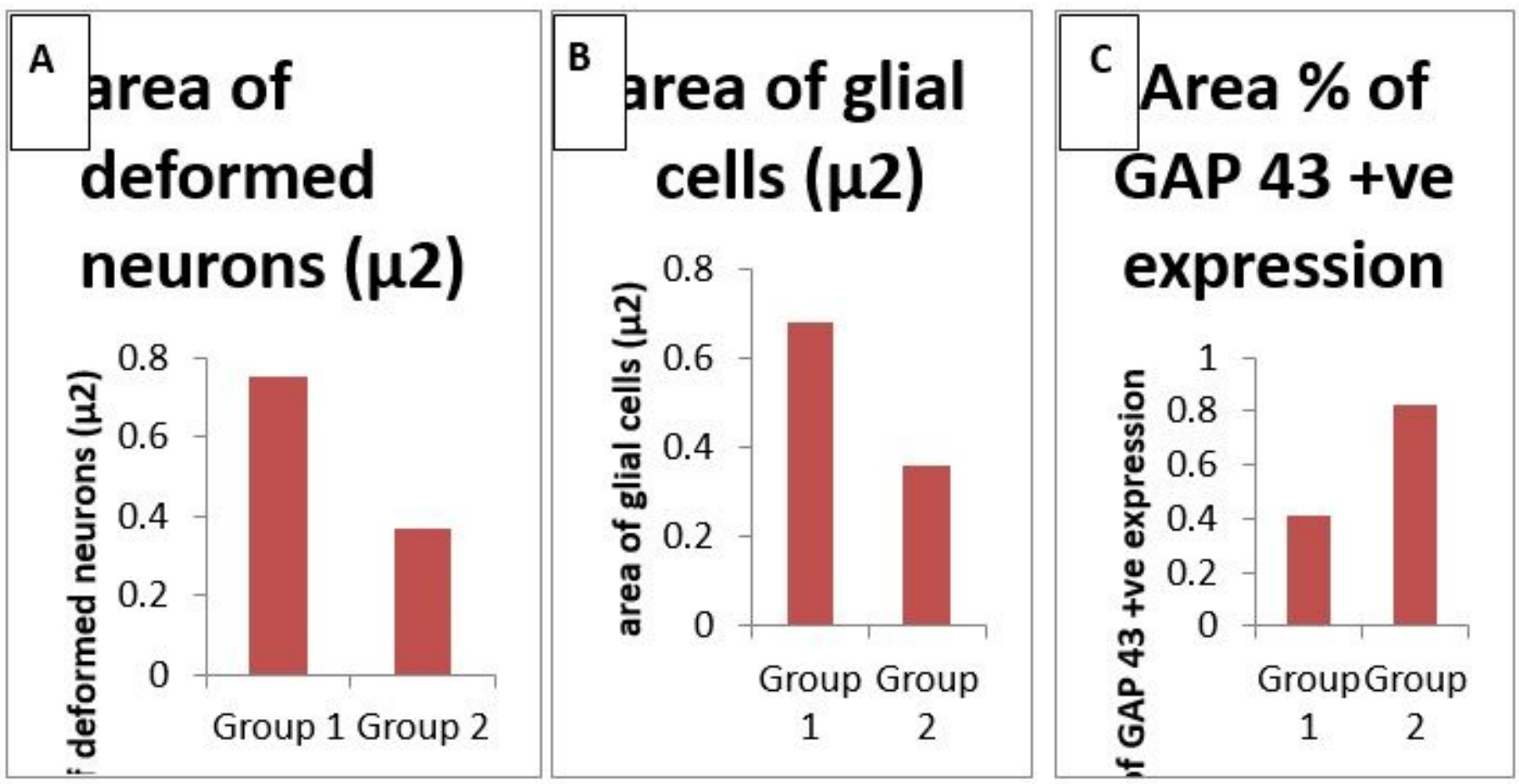


\section{Figure 10}

Graphic representation of the mean area of (A) deformed neurons (B) glial cells (C) +ve GAP 43 expression, in cerebral cortex sections of group 2 in comparison to group1. Group 1: Mice with induced neuronal degeneration receiving no therapeutic intervention. Group 2: Mice with induced neuronal degeneration treated with non-modified MSCs.
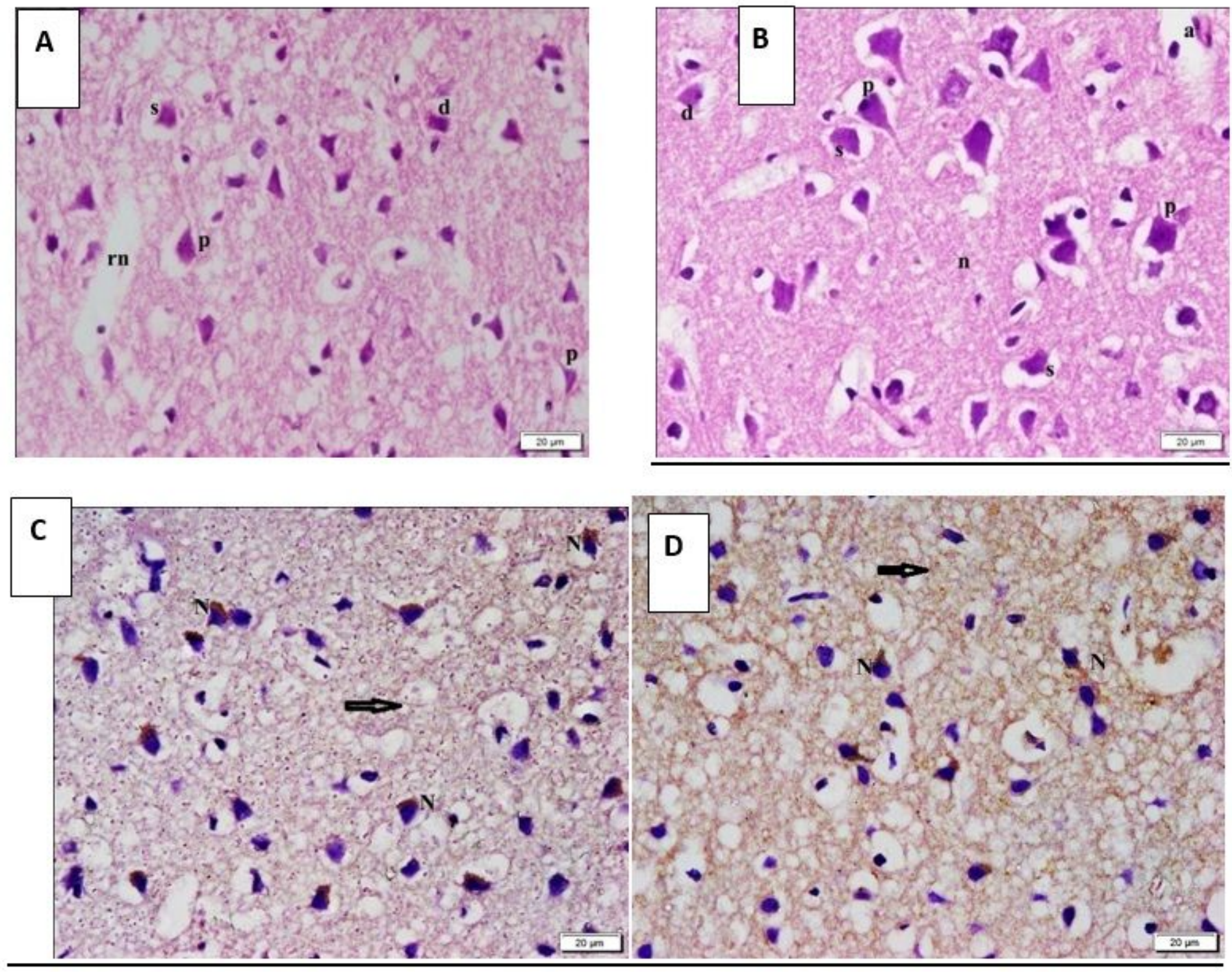

\section{Figure 11}

Section of cerebral cortex of mouse from (A) subgroup 2a showing few deformed neurons (d) and rarified neuropuil (rn). Note some pyramidal (p) and stellate (s) neurons. (H\&E, x400) (B) subgroup 2b showing few deformed neurons (d), accidental neurons with acidophilic cytoplasm and dark nuclei (a). Note multiple pyramidal (p) and stellate (s) neurons, the neuropil (n) is apparently normal. (H\&E, x400) (C) subgroup 2a showing positive GAP43 IE in some neurons $(\mathrm{N})$ and obvious IE among the neuropil $(\uparrow \uparrow)$ 
(GAP43 immuno-staining x400 (D) sub group 2b showing positive GAP43 IE in multiple neurons (N) and obvious IE among the neuropil ( $\uparrow$ ) (GAP43 immuno-staining x400).
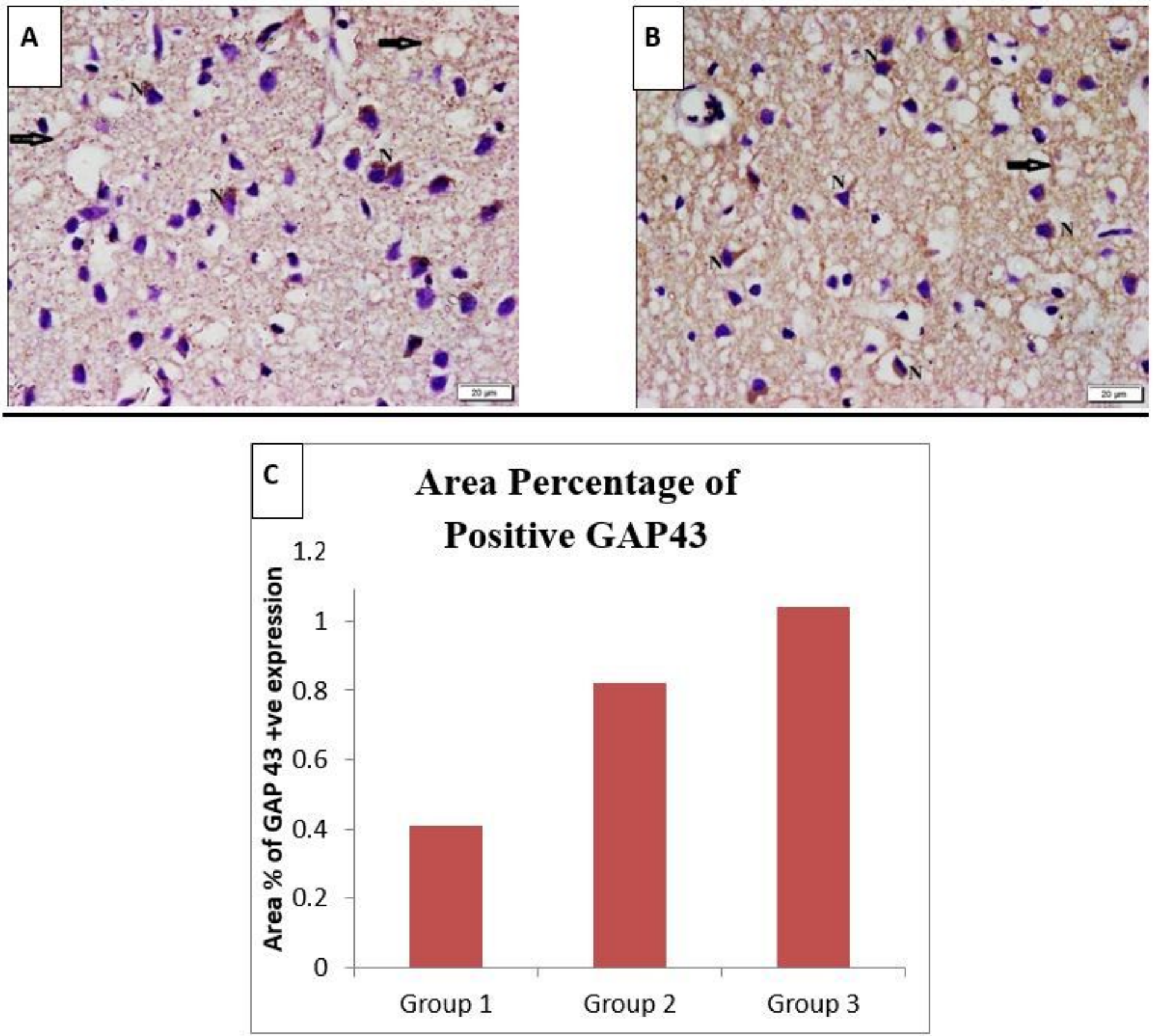

Figure 12

(A) Section of cerebral cortex of a mouse from subgroup 3a stained by GAP43 immune staining showing positive GAP43 IE in multiple neurons $(\mathrm{N})$ and obvious IE among the neuropil ( $\uparrow$ ) (GAP43 immunostaining $\times 400)$.(B) Section of cerebral cortex of a mouse from subgroup 3b stained by GAP43 immune staining showing positive GAP43 IE in numerous neurons $(\mathrm{N})$ and obvious IE among the neuropil $(\uparrow \uparrow)$ (GAP43 immuno-staining x400).(C): Graphic representation of the Immunohistochemical study for the mean area \% of positive GAP 43 expression in groups 1, 2 and 3. Group 1: Mice with induced neuronal degeneration receiving no therapeutic intervention. Group 2: Mice with induced neuronal degeneration 
treated with non-modified MSCs. Group 3: Mice with induced neuronal degeneration treated with modified MSCs.
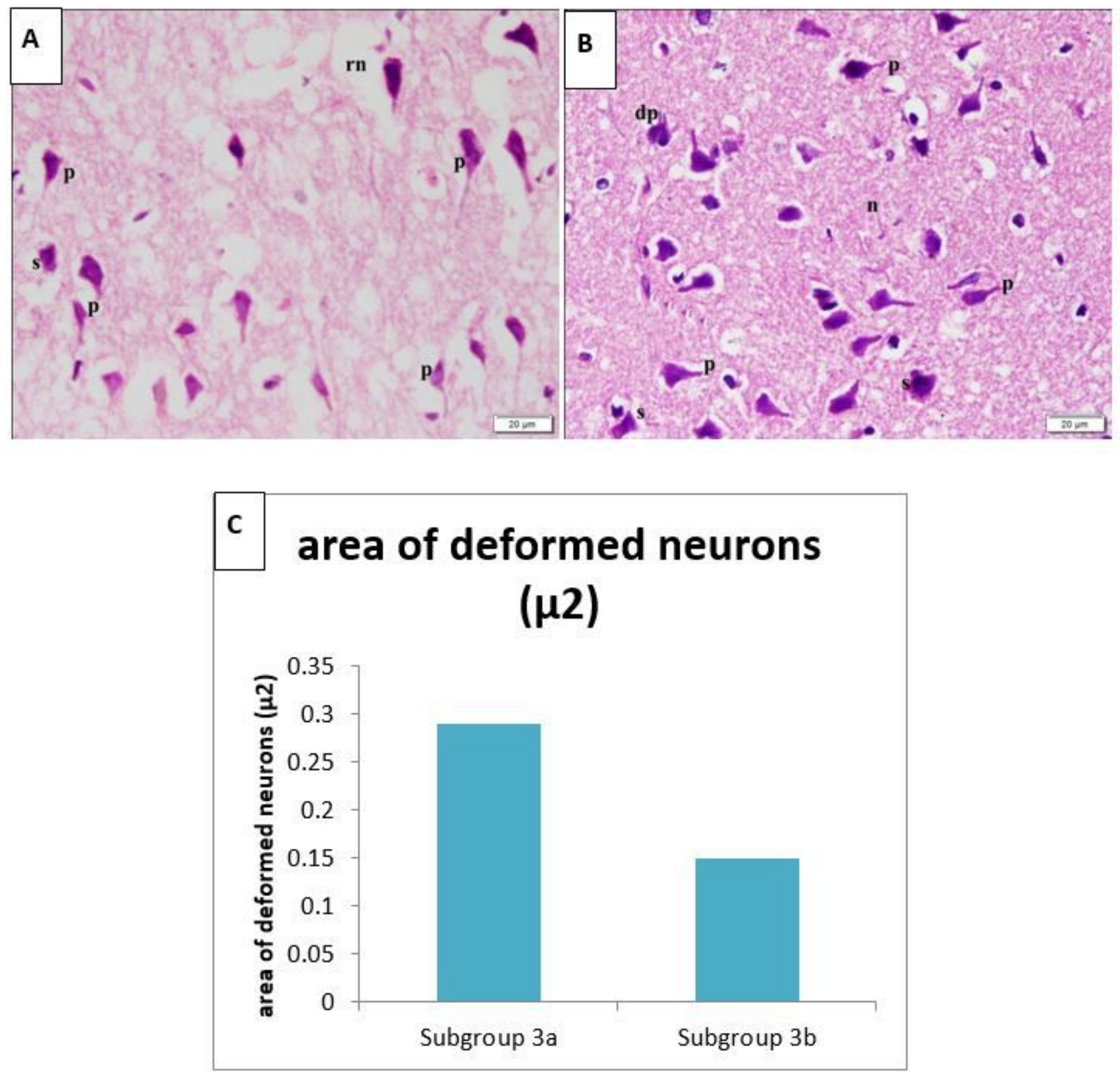

Figure 13

(A) Section of cerebral cortex of mouse from subgroup 3a showing accidental deformed neurons (d), rarified neuropil (n), multiple pyramidal ( $p$ ) and stellate (s) neurons (H\&E, x400). (B) Section of cerebral cortex of mouse from subgroup $3 b$ showing accidental deformed neurons (d), multiple pyramidal $(p)$ and stellate (s) neurons, in addition to apparently normal neuropil (n). Note duplicated pyramidal neurons (dp) (H\&E, x400). (C): Graphic representation of the mean area of deformed neurons in subgroup 3a in 
comparison to subgroup 3b Subgroup 3a: Mice with induced neuronal degeneration treated with modified MSCs sacrificed 7 days after stopping the neurodegenerative drug. Subgroup 3b: Mice with induced neuronal degeneration treated with modified MSCs sacrificed 14 days after stopping the neurodegenerative drug. 